\title{
Inguinal Gravid Hysterocele in Feline
}

\author{
Rebeca dos Santos Costa', Deusdete Conceição Gomes Junior'², Aline da Trindade Quintela Santos', \\ João Moreira da Costa Neto ${ }^{3}$, Levi Oliveira dos Santos' ${ }^{1}$, Débora Passos Hinojosa Schaffer', \\ Egberto de Almeida Cardoso Neto' \& Milena de Almeida Pinheiro Cardoso Maciel ${ }^{4}$
}

\begin{abstract}
Background: Hysterocele is an inheritance rare in feline, characterized by the protrusion of the uterus by the inguinal channel, a situation related with the congenital abnormality of the inguinal ring, allowing the protrusion of abdominal contents for the subcutaneous space. As differential diagnosis of hysterocele are the breast cancer, abscesses and bruises and image exams such as radiography and ultrasonography have large relevance for identifying the disease and, additionally, clarify the hernia content. The purpose of this study was to describe one case report of the inguinal gravid hysterocele in a cat.

Case: A 1-year-old female feline, without history of trauma of increase of volume in the inguinal region was referred for clinical evaluation. Due to the presence of three gestational vesicles, the decision by following-up the fetal development was taken, by means of periodical ultrasound evaluations, for performing operative procedure. At 56 days of gestation, when intestinal peristaltic movements of the three kittens were observed, cesarean was indicated. The procedure began by an oblique incision in the left retro-umbilical region, however, due to adhesions, there was no proper uterine exposition for hysterotomy. Retro-umbilical celiotomy, adhesiolise and return of the uterus for the abdominal cavity were performed in order to execute the cesarean followed by ovariohysterectomy. The hernial ring was debrided and sutured in order to keep patent the inguinal ring. No post-operatory complications were noted indicating that the established conduct allowed the survival of the parturient and its kittens.

Discussion: In a casuistic study where data from 1988 until 2007 were collected, from the Faculty of Veterinary Medicine from the University of São Paulo, a higher occurrence of inguinal hernias was observed in female dogs, when compared with male dogs and, until that period, the inguinal hernia was not reported in the feline species. It is known that the inguinal ring may dilate with the obesity and increase of the intra-abdominal pressure, linked with the weakening of the adjacent structures. Besides, the appearance of hysterocele in females is also related with the estrus or gestation, caused by the hormonal imbalance, leading to the weakening of the conjunctive tissue, resulting in the enlargement of the inguinal rings, which is according to what was observed in this report where the animal was pregnant. Additionally, the application of contraceptive (progestin's) could have accentuated the muscle fragility, favoring the projection of the uterus by the inguinal ring. In most of the cases described in literature, animals have no discomfort to the handling of the herniated content however, for some authors, the prolongation of surgical resolution may aggravate the clinical condition, predisposing the formation of adherences that may cause discomfort or pain, particularly when the bladder or intestinal loops are involved, resulting in difficulty urinating and defecating, respectively. Care must be taken during the reduction of the inguinal ring, in order to avoid compromising the external pudendal artery and vein, and of the genito-femoral nerve, which emerge from the tail-medial aspect of the ring. In this study, it was tried to perform the hernia suture in a way that the inguinal ring remained patent. On the same way that was performed in this study recommend the execution of ovariohysterectomy in order to avoid relapse and because it is an hereditary condition. The inguinal gravid hysterocele in feline may be adequately manage until the ideal moment for cesarean without prejudice to the parturient and to its products.
\end{abstract}

Keywords: inguinal hernia, cat, uterus. 


\section{INTRODUCTION}

Hysterocele is an inheritance of low frequency in canine and rare in feline, characterized by the protrusion of the uterus by the inguinal channel, a situation related with the congenital abnormality of the inguinal ring, allowing the protrusion of abdominal contents for the subcutaneous space $[7,8,13]$. Situations leading to the increase of intra-abdominal pressure such as gestation, obesity and pyometra may be associated with the formation of inguinal hysterocele and, it is also speculated that the hormonal imbalance promotes the weakening of connective tissue resulting in the enlargement of the hernia ring $[3,11]$.

As differential diagnosis of hysterocele are the breast cancer, abscesses and bruises [11,13]. Image exams such as radiography and ultrasonography have large relevance for identifying the disease and, additionally, clarify the hernia content $[3,8]$.

The proposed treatment in the immediate surgical correction, aiming to prevent complications associated with strangulation. Thus, in cases of hysterocele, the ovariohysterectomy and reduction of the hernia ring are performed, in order to avoid the formation of new inguinal hernias. The prognosis is usually favorable for most of the cases $[6,10]$. In the presence of pregnant uterus in the hernia content, the inguinal hysterocele becomes called inguinal gravid hysterocele and the procedure to be taken will depend upon the gestation time and fetal viability.

This study aimed to report a case of inguinal gravid hysterocele in feline treated the veterinary hospital from the "União Metropolitana de Educação e Cultura (Hosvet-Unime)", in Lauro de Freitas, Bahia, Brazil.

\section{CASE}

A 1-year-old female feline was treated in the "Hosvet-Unime" of Lauro de Freitas, Bahia, Brazil. It had a history of volume increase in the mammary region at about 20 days. The tutor reported application of contraceptive 30 days ago and that there was no previous history of trauma or increase of volume in the inguinal region. At clinical examination the patient was active, physiological parameters inside the standards of normality for the species and, during abdominal palpation, an increase of volume in the left inguinal region was observed (Figure 1B), of soft consistency and painless, non-reducible. Laboratory tests (blood count and creatinine) were requested, which did not reveal alterations. Abdominal ultrasound indicate the presence of three gestational vesicles with viable fetuses of approximately 41 days (Figure 1A).

In face of the clinic findings and due to the absence of fetal maturation and the fact that the patient was comfortable, the option was to periodically followup the gestational condition. At 56 days of gestation, when intestinal peristaltic movements of the fetuses were observed, cesarean was indicated.

After antisepsis care the animal was induced with propofol $4 \mathrm{mg} \mathrm{kg}^{-1}$ (Propovan $\left.{ }^{\circledR}\right)^{1}$ intravenously, orotracheal intubation was performed and lumbosacral epidural block $\left(\text { Xylestesin }^{\circledR}\right)^{1}$.

Operative procedure began by means of an oblique cut incision in the left retro-umbilical region, for accessing the inguinal hernia. The hernia content was composed by intestinal loops, omentum, fat and portion of both uterine horns, with adhesions in adjacent tissues that prevented the proper exposition for the hysterotomy. Then ventral median laparotomy was executed where, after adhesiolysis, the uterus could be returned to the abdominal cavity and cesarean proceeded. Due to constrictions in the uterine horns, the kitten could not be removed towards the uterine body, being necessary to perform incision in each uterine horn for removing the fetuses. After removing the kittens, followed inhalation anesthesia with isoflurane (Isoforine $\left.{ }^{\circledR}\right)^{1}$ diluted in oxygen at $100 \%$. Because it is a hereditary disease and in order to avoid relapse, next ovariohysterectomy was executed routinely.

The hernia ring was fixed by means of debridement of its edges, followed by approximation with polyglycolic acid suture $\left(\text { Polycryl }^{\circledR}\right)^{2}$, in Sultan

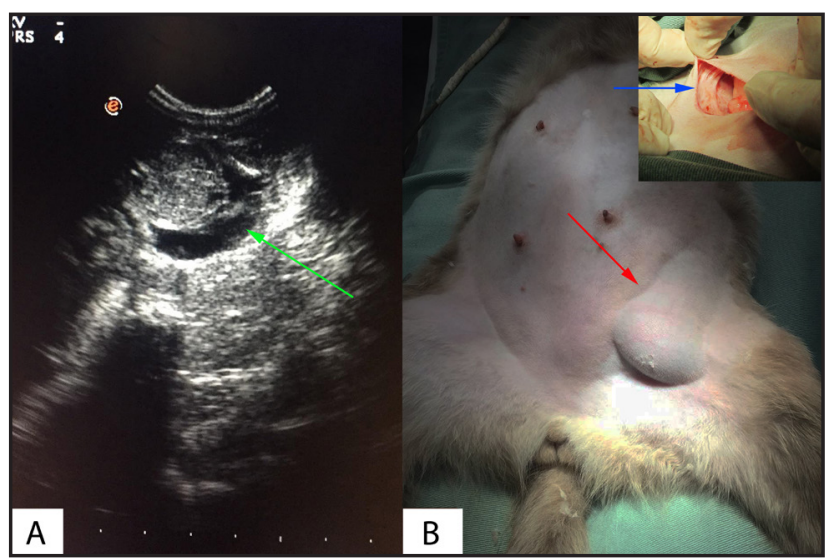

Figure 1. Gravid hysterocele in feline. A- Ultrasonography image where one gestational vesicles (green arrow) are visible, with viable fetuses of approximately 41 days. B- Patient in dorsal decubitus, under total intravenous anesthesia associated with epidural, with increased volume in the left inguinal region (red arrow). In detail inguinal ring enlargement (blue arrow). 
standard, in order to make clear the inguinal ring. Abdominal cavity was closed routinely. Meloxicam $\left(\text { Maxicam }^{\circledR}\right)^{3}$, SID, for three days, and dipyrone 25 $\mathrm{mg} \mathrm{kg}^{-1}$ (generic drug) ${ }^{4}$, TID, for five days were prescribed. Eight days after operative procedure the patient returned for removing the stitches from the skin, the surgical wound had good aspect and healed. No postoperative complications were observed.

\section{DISCUSSION}

Inguinal hernias, although uncommon, happen more frequently in female dogs, being considered as a very rare condition in female cats [4,9]. In a casuistic study where data from 1988 until 2007 were collected, from the Faculty of Veterinary Medicine from the University of São Paulo, a higher occurrence of inguinal hernias was observed in female dogs, when compared with male dogs and, according to the authors, until that period, the inguinal hernia was not reported in the feline species [1]. Due to the absence of records in the searched literature, the case of inguinal hysterocele with pregnant uterus in female cat raised the interest of the authors.

It is known that the inguinal ring may dilate with the obesity and increase of the intra-abdominal pressure, linked with the weakening of the adjacent structures. Besides, the appearance of hysterocele in females is also related with the estrus or gestation, caused by the hormonal imbalance, leading to the weakening of the conjunctive tissue, resulting in the enlargement of the inguinal rings $[6,13]$, which is according to what was observed in this report where the animal was pregnant. Additionally, the application of contraceptive (progestin's) could have accentuated the muscle fragility, favoring the projection of the uterus by the inguinal ring.

Descriptions of reports of hysterocele in female dogs point that they happen more frequently at the left side $[1,12,14]$, fact also observed in this report. It is highlighted that the searched literature does not justify the greater casuistry of involvement at the left side.

In most of the cases described in literature, animals have no discomfort to the handling of the herniated content $[12,14]$. However, for some authors, the prolongation of surgical resolution may aggravate the clinical condition, predisposing the formation of adherences that may cause discomfort or pain, particularly when the bladder or intestinal loops are involved, resulting in difficulty urinating and defecating, respectively $[8,12,14]$.

According to the literature $[13,15]$ the pregnant uterus, with pyometra or hematometra may cause severe systemic alterations, such as toxemia, resulting from inefficient or obstructed drainage of the uterus. In this report, due to the immaturity of the viable fetuses and stability of the patient, it was opted by periodical follow-up until fetal maturity for then performing cesarean followed by herniorrhaphy.

Some reports in literature used dissociative anesthesia for resolution of inguinal hernias in female dogs, include patients with inguinal gravid hysterocele $[5,8,12,16]$. It is highlighted that the anesthetic protocol must be based on the available anesthetic drugs, experience and preference of the anesthetist besides the health condition of the patient [2]. The epidural is the ideal technique for cesarean because it promotes adequate anesthesia and analgesia, without depressing the mother, thus avoiding fetal depression.

Care must be taken during the reduction of the inguinal ring, in order to avoid compromising the external pudendal artery and vein, and of the genito-femoral nerve, which emerge from the tail-medial aspect of the ring [13]. In this study, it was tried to perform the hernia suture in a way that the inguinal ring remained patent. On the same way that was performed in this study $[6,13,15]$ recommend the execution of ovariohysterectomy in order to avoid relapse and because it is an hereditary condition.

The feline inguinal gravid hysterocele, despite being rare, may I adequately manage until the ideal moment for cesarean. This management may be by means of periodic ultrasonography evaluations, without prejudice to the parturient and to its products.

Declaration of interest. The authors report no conflicts of interest. The authors alone are responsible for the content and writing of the paper.

\section{MANUFACTURERS}

${ }^{1}$ Cristália Produtos Químicos e Farmacêuticos. Itapira, SP, Brazil. ${ }^{2}$ Polysuture Industria e Comércio Ltda. São Sebastião do Paraíso, MG, Brazil.

${ }^{3}$ Maxicam, OuroFino Saúde Animal Ltda. Cravinhos, SP, Brazil. ${ }^{4}$ EMS S.A. São Bernardo do Campo, SP, Brazil.

\section{REFERENCES}

1 Cruz-Pinto C.E., Stopiglia A.J., Matera J.M. \& Arnoni F.I. 2015. Análise da casuística das afecções cirúrgicas observadas na Clínica Cirúrgica de Pequenos Animais da FMVZ-USP no período de 1988 a 2007. Brazilian Journal of Veterinary Research and Animal Science. 52(1): 41-47.

2 Luz M.R., Freitas P.M.C. \& Pereira E.Z. 2005. Gestação e parto em cadelas: fisiologia, diagnóstico de gestação e 
tratamento das distocias. Revista Brasileira de Reprodução Animal. 29(3/4): 142-150.

3 Martin K.D.J., Philip S.B., Sarangom S.B. \& Kankonkar A.P. 2012. Bilateral inguinal hernia with distinct hysterocele and omentocele in a dachshund bitch. Journal of Indian Veterinary Association. 10(1): 45-47.

4 Matera E.A., Stopiglia A.V. \& Marcondes Veiga J.S. 1960-62. Histerocele inguinal da cadela. Revista da Faculdade de Medicina Veterinária. 6(4): 457-467.

5 Nak Y., Misirlioglu D., Nak D., Tuna B., Kumru I.H. \& Alasonyalilar A. 2004. Findings of focal adenomyosis in a case of inguinal hysterocele accompanied with mammary tumour in a bitch. Journal of the Faculty of Veterinary Medicine. 23(1/3): 99-102.

6 Oliveira S.N., Araujo E.A.B., Silva L.F.M.C., Dalanezi F.M., Zahn F.S. \& Prestes N.C. 2016. Alta incidência de histerocele em cadelas atendidas em um Hospital Veterinário. Veterinária e Zootecnia. 23(2): 231-234.

7 Park C.H., Kim B.S., Lee J.H., Kim J.H., Kim H.S., Mun B.G., Lee C.Y., Suh G.H., Bae C.S., Kang S.S., Son C.H. \& Oh K.S. 2008. Pyometra with Inguinal Herniation in a Dachshund Dog. In: 15th Congress of the Federation of Asian Veterinary Association (Bangkok, Thailand). pp.331-332.

8 Prasad V.D., Mahesh R., Kamalakar G., Devarathnam J. \& Kumar R.V.S. 2016. Surgical Management of Inguinal Gravid Hysterocele in a Bitch. The Indian Veterinary Journal. 93(5): 58-60.

9 Raiser A.G. 1994. Hérnia inguinal em cães - Relato de 26 casos. Ciência Rural. 24(3): 551-556.

10 Sainulabeen A., Nair S. \& Devanand K.S. 2016. Inguinal hysterocoele and its surgical management in a female dachshund dog. Malaysian Journal of Veterinary Research. 7(2): 31-34.

11 Serin G., Yaygingul R., Tarimcilar T. \& Sarierler M. 2009. An incarcerated inguinal hysterocele in a pregnant bitch: a case report. Veterinarni Medicina. 54(8): 382-386.

12 Simon S.M., Ramprabhu R. \& Prathaban S. 2013. Surgical management of concurrent inguinal hysterocele, cystocele and epiplocele in a bitch. Journal Intas Polivet. 14(1): 127-128.

13Smeak D.D. 2012. Abdominal Wall Reconstruction and Hernias. In: Tobias K.M. \& Johnston S.A. (Eds). Veterinary Surgery in Small Animal. St. Louis: Elsevier Saunders, pp.1353-1382.

14 Sontas B.H., Toydemir F.T.S., Erdogan O., Sennazli G. \& Ekici H. 2013. Inguinal herniation with hydrometra/ mucometra in a poodle bitch. The Canadian Veterinary Journal. 54(9): 840-844.

15Sturion D.J., Sturion T.T., Strurion M.A.T., Garcia B.A., Martins E.L. \& Moya-Araujo C.F. 2013. Histerocele inguinal com hematometra em cadela - Relato de Caso. Arquivos de Ciências Veterinárias e Zoologia da UNIPAR. 16(2): 165-168.

16 Vijayakumar M., Arunprasad A. \& Pushkinraj H. 2016. Surgical Management of Entero-Hystero-Cystocele in a bitch. Journal of Agriculture and Veterinary Science. 9(10): 30-32. 